UDC 617.753.2

DOI: $10.21668 /$ health.risk/2019.3.03.eng

\title{
ANALYSIS OF RISK FACTORS THAT CAUSE MYOPIA IN PRE-SCHOOL CHILDREN AND PRIMARY SCHOOL STUDENTS
}

\author{
E.P. Tarutta, O.V. Proskurina, N.A. Tarasova, G.A. Markosyan
}

Helmholtz's National Medical Research Center of Eye Diseases, 14/19 Sadovaya-Chernogryazskaya Str., Moscow, 105062, Russian Federation

The article summarizes literature data on significant risk factors that cause myopia in children; it also dwells on an algorithm that can be applied by ophthalmologists, pediatricians, family doctors, and medical optometrists to determine risk groups as per myopia, to accomplish dynamic observation, and to implement medical and prophylaxis activities aimed at its prevention. A hereditary factor in myopia development is considered to be the most significant one. There are also several other significant factors such as refraction being greater than +0.75 diopter at an age 6-10; an anterior-posterior axis of the eye being longer than $23.5 \mathrm{~mm}$; pseudo-myopia; relative accommodation resources being lower than 1.0 diopter; axial length over cornea radius ratio $(A L / C R)$ being higher than 3; accommodative convergence over accommodation ratio (AC/A) being higher than 4 pr.diopter / diopter; relative peripheral hypermetropia and off-axis refraction asymmetry when the nasal side of the eye is higher than the temporal one. We paid special attention to influences exerted by the environment and urbanization. High educational and social status of a family results in elevated risks of myopia. We also spotted out several risk factors that could be eliminated; they were hypodynamia under great visual loads and a period of time spent outdoors being shorter than 10 hours a week. Reliable preventive measures include parents' control over visual activities of a child; imposing limits on visual loads; outdoor activities for not less than 10-14 hours a week; physical exercises and doing some sports; home training to improve accommodation; correction aimed at compensating peripheral hypermetropia and lor inducing myopic defocus; local medical treatment. Early detection of risk factors and direct or indirect influence on them allow preventing myopia or postponing its development for an older age; it results in lower frequency of significant myopia and reduces a number of complicated and severe myopia cases.

Key words: myopia in children, risk factors, myopia development, myopia prevention, myopia predictors, refraction disorders, peripheral refraction.

Myopia is the most common type of disproportionate refraction; it is more frequently an acquired disorder. Myopia usually develops when a child starts school but its earlier occurrence in children - during preschool years - becomes more and more frequent $[1,2]$. Frequency of myopia differs substantially across the world. This type of refraction is most frequently detected in countries located in South-Eastern Asia where prevalence of myopia exceeds $90 \%$ as per data taken from several sources $[3,4]$. In Europe myopia is not so widely spread but still its prevalence among population is greater than 35\% [5]. In some regions in Russia $2.4 \%$ children are already near-sighted when they just start school. By the fifth grade a number of near-sighted children grows by 8 times (!) reaching 19.7\%. By the last school year prevalence of myopia among schoolchildren is close to average European level and amounts to $36.8 \%$ [2]. There is even a

(C) Tarutta E.P., Proskurina O.V., Tarasova N.A., Markosyan G.A., 2019

Elena P. Tarutta - Doctor of Medical Sciences, Professor, Head of the Department for Refraction Pathologies, Binocular Eyesight, and Ophthalmologic Ergonomics (e-mail: kanc@igb.ru; tel.: +7 (495) 608-42-00; ORCID: https://orcid.org/0000-0002-8864-4518).

OI ga V. Proskurina - Doctor of Medical Sciences, Leading Researcher at the Department for Refraction Pathologies, Binocular Eyesight, and Ophthalmologic Ergonomics (e-mail: proskourina@mail.ru; tel.: +7 (916) 169-11-14; ORCID: https://orcid.org/00000002-2496-2533).

Natalya A. Tarasova - Candidate of Medical Sciences, Senior Researcher at the Department for Refraction Pathologies, Binocular Eyesight, and Ophthalmologic Ergonomics (e-mail: kanc@igb.ru;tel.: +7 (495) 608-42-00; ORCID: https://orcid.org/0000-0002-3164-4306).

Gayane A. Markosyan - Doctor of Medical Sciences, Leading Researcher at the Department for Refraction Pathologies, Binocular Eyesight, and Ophthalmologic Ergonomics (e-mail: kanc@igb.ru; tel.: +7 (495) 608-42-00; ORCID: https://orcid.org/0000-0002-2841-6396). 
concept stating that there is "epidemic of myopia" $[3,4]$. The WHO program 'Control and prevention of blindness and deafness by 2020 " determines myopia as one of five priority diseases that require active prevention of eliminable blindness.

Meta-analysis performed by Brien Holden Vision Institute on 2.1 million participants revealed that there should be a significant rise in a number of short-sighted people all over the world from 2000 to 2050. As predicted, by 2050 there will be 4.8 billion short-sighted people in the world or, in other words, $49.8 \%$ of the overall world population. And almost 1 billion people will suffer from high myopia [6]. Myopia causes 3 times higher risks of early acquired cataract; 8 times higher risks of retina rapture; 18 times higher risks of glaucoma [7]. And if myopia develops at an early age, it is the most established factor for consequent occurrence of high myopia $[1,8]$.

Although all contemporary techniques aimed at controlling myopia are quite efficient, a greater attention should be paid to detecting risk factors that cause myopia in preschool and junior school children if we want to prevent its spread. It is also very important to prevent its development, especially at early stages of the disease.

This paper focuses on generalizing all the available literature data on risk factors that cause myopia and their ranking; there is an algorithm which we recommend to ophthalmologists, pediatricians, family doctors, and medical optometrists as they can apply it to create risk groups as per myopia, to perform dynamic observation, and to implement relevant treatment and prophylaxis aimed at preventing myopia.

There are a lot of scientific works, especially by foreign authors, that concentrate on determining risks of myopia occurrence in children. We thoroughly analyzed these works and it allowed us to reveal the most significant and convincing factors that cause risks of myopia.

Heredity. It is quite possible that a child becomes near-sighted even if he or she doesn't have any relatives (parents or more remote ones) who suffer from myopia. Chances that such children might have myopia are equal to 0.28 ; but if both parents of a child are nearsighted, chances grow to 0.85 and continue to increase with each subsequent generation [9]. Obviously, the reverse situation is also possible when near-sighted parents have children with normal vision but it is rather rare. A simple calculation shows that chances for it are equal to not more than 0.12 . It is heredity that makes a significant contribution into probability of myopia occurrence. Thus, a child who has at least one near-sighted parent runs 2-3 times higher risks of myopia than a child whose parents have normal vision. Most researchers confirm that having two near-sighted parents causes 1.5-2 times higher risk of myopia for their children [1,8,9, and 10].

Sex. We haven't found any convincing data on a sex being a factor that can cause elevated risks of myopia.

Ethnic groups. Multiple research works prove that prevalence of myopia is significantly higher among people coming from Eastern Asia, notably Chinese, than among Europeans (Caucasians) and other ethnic groups [1, 3, 4, 5, and 11].

The environment, education, and urbanization. There are a lot of convincing evidences that there is a tight correlation between genetic factors and impacts exerted by the environment [1, 3, and 10]. Experts comparatively analyzed refraction of Sherpa children who lived in rural areas and children from Tibet who lived in Katmandu (the capital of Nepal); those children had the same ancestors but lived in drastically different educational and ecological conditions. The analysis revealed that myopia was considerably less frequent among Sherpa children $(2.9 \%)$ than among their counterparts living in a city $(21.7 \%)$ [12]. We may state that high prevalence of myopia results from adaptation to impacts exerted by ecological changes, better education that is indirectly linked to a higher social and economic status, and urbanization $[1,3,13]$. The latter 
in its turn is linked to many environmental factors that produce direct or indirect effects on prevalence of myopia. Researchers examined factors that caused myopia among Chinese children and revealed that multi-factor and polygenic models prevailed in the process and genetic factors remained constant in them whereas influence exerted by the environment had been growing during lives of the last three generations [10]. Myopia prevalence remained the same in different ethnic groups exposed to the same environmental conditions in spite of significant genetic differences.

Time a child spends outdoors, duration of work at a short distance, sight hygiene, and family. Recent research confirms the result obtained via previous one performed by E.S. Avetisov [14]: if children spend sufficient amount of time outdoors, it reduces risks of myopia. The most significant factor here is a balance between time a child spends on working at a short distance from objects and time he or she spends outdoors [3, 15]. Thus, 12-year old children who spend less than 1.6 hours outdoors a day and have additional 3 hours of educational loads beyond school acquire myopia 2-3 times more frequently than children of the same age who spend more than 2.8 hours outdoors and with additional educational loads being less than 2 hours [16]. A simple change in a day schedule - children spending their breaks outdoors - leads to a more than a 2-time reduction in risks of myopia among children aged $7-11$ as calculated risks of myopia amounted to $8.41 \%$ among children who spent their school breaks outdoors and to $17.65 \%$ among those who didn't do it [17]. To sum up, increased amount of time spent outdoors leads to a 2-time reduction in risks of myopia as well as makes for slower development of already existing myopia [18]. Some authors state that physical activities and doing sports outdoors during 7-14 hours a week is quite a reliable factor that can prevent myopia occurrence $[19,20]$. Children aged 7-9 who read two or more books a week run a three times higher risk of myopia as compared to those children who read two or fewer books a week [21, 22]. Children aged 12-13 who hold a book at a distance equal to $29 \mathrm{~cm}$ or less when reading run 2.5 times higher risk of myopia; uninterrupted reading that lasts for longer than 30 minutes results in 1.5 times higher risks of myopia [21]; 6-year old children who work at a short distance from objects for more than 1 hour a day run 1.26 times higher risk of myopia [23]. However, if we take into account other significant factors (such as belonging to a specific ethnic group, for example), we should specify that intensity is a leading factor and not a period of time spent working at a short distance from objects. Children who suffered from myopia were compared with children who had normal vision; it turned out that near-sighted children more frequently had near-sighted parents; they spent much more time on educational tasks, more time on reading, and less time on doing sports; they tended to have higher scores in reading ITBS tests and overall language sub-tests [24]; they attended grammar schools; they watched TV or played computer games, videogames or games on their smartphones for more than 2 hours a day; their families had higher social status [19]. Our previous research also revealed that myopia was much more frequent among children who attended specialized grammar schools as compared to those who attended "ordinary" comprehensive schools [2].

Greater attention paid by parents to visual activities of their children can substantially reduce risks of myopia occurrence. Control over use of electronic devices resulted in more than 2-rtime decrease in risks of myopia. Other significant factors were control over a child getting sufficient amount of sleep, a posture he or she took when doing homework, and amount of time a child spent outdoors. The earlier parents started to pay attention to those factors the lower was risk of myopia for their children at an early age and the better were refraction and functional results at an older age [13]. 
Axial refraction. Data collected via observation cohort study revealed that cycloplegic sphere equivalent of refraction that is stronger than 0.75 diopter hypermetropia in children younger than 6 is the most authentic predictor that myopia will occur in future, the probability being 95\%. Refraction that is stronger than 0.5 diopter hypermetropia is a myopia predictor for 6-year old children; emmetropia is a predictor for children aged 7-8 [25]. According to some other data, hypermetropia that is lower than 0.75 diopter is a real risk factor that causes myopia in children up to 11 years of age $[8,11]$. Refractometry data in case there is cycloplegia can be a sufficient ground for including a child into a risk group as per myopia.

Axial length of an eye and refracting power of the cornea. Axial length that is greater than $23.5 \mathrm{~mm}$ correlates with high risks of myopia among 6-year old children with normal vision regardless of their genetic background [11]. Anterior-posterior axis length that is greater than $24.33 \mathrm{~mm}$ can be a risk factor that causes myopia among children aged 10-14 [26]. Axial length (mm) over cornea radius $(\mathrm{mm})$ ratio $(\mathrm{AL} / \mathrm{CR})$ that is higher than 3 can be a more reliable predictor of myopia occurrence among children aged 6-12 [27]. Radius of horizontal meridian curvature is more informative in such calculations.

Off-axis refraction (peripheral refraction) and length of an eye. Initial form of an eye can be a risk factor that causes myopia. Relative peripheral hypermetropic refraction is considered a reliable myopia predictor as children who acquired myopia tended to have more significant relative peripheral hypermetropia $2-5$ years prior to becoming nearsighted that those who preserved normal vision $[11,25]$. There was a study that concentrated on contours of the retina via determining a discrepancy between axial and off-axis length of an eye in a $20^{\circ}$ zone; 140 children aged from 7 to 11 were examined twice with a 30-month interval between two checkups. The study revealed a significant correlation between myopia occurrence and initially steeper contour of the retina from the temporal side. Steeper contour of the retina from the temporal side implies there is relative peripheral long sight in this part of the retina or weaker refraction in the temporal zone as compared with the nasal one [28]. A difference in an extent to which the nasal and temporal parts of an eye contribute into myopia occurrence is confirmed by measurement of off-axis refraction during accommodation. Off-axis refraction in $40^{\circ}$ zone in the retina of a short-sighted eye changes weaker than in an eye with normal vision by 1.1 diopter in the nasal zone and by 1.7-2.0 diopter in the temporal one during accommodation tasks that are performed at $25 \mathrm{~cm}$ distance. Risks of myopia are assumed to grow if an eye doesn't change retina curvature when performing its tasks [29].

Accommodation. Weaker accommodation response can be treated as an independent myopia predictor [30, 31, and 32]. Special attention is paid to a low-bent head when any task is performed at a close distance $[14,21]$ and a decrease in relative accommodation resources: children who later acquired myopia had lower relative accommodation resources (1.46 diopter) than those who preserved their normal vision (2.04 diopter) [32].

Pseudomyopia is a symptom that is considered to be a specific myopia predictor by mostly Russian researchers. The Expert Council on Accommodation and Refraction (ECAR) determines pseudomyopia as a state when manifest refraction is emmetropic, and cycloplegic refraction is either emmetropic or even hypermetropic. A.I. Dashevskiy (1988) believed that pseudomyopia always preceded actual near-sightedness [33]. Pseudomyopia occurrence leads to 3.03 times higher risks of myopia and it preceded axial myopia in $77.8 \%$ of children who had it [26].

Heterophoria and $\mathrm{AC} / \mathrm{A}$ ratio. Heterophoria which is higher than 3 prism diopter (pr.diopetr) is an obvious risk factor that can cause myopia in children; greater attention here is paid to esophoria $[32,34]$. Accom- 
modative convergence over accommodation $(\mathrm{AC} / \mathrm{A})$ ratio is more informative in this respect. An increase in AC/A ratio can be detected 4 years prior to myopia occurrence and is equal to 7 pr.diopter/diopter in children who run high risks of myopia occurrence. This ratio is authentically lower in children who will potentially preserve their normal vision and remains equal to 4 pr.diopter/ diopter; it is probably due to a greater lag in accommodation in children who can become near-sighted [34]. Previous research revealed that risk of myopia occurrence grew by 22.5 times during 1 year for children with $\mathrm{AC} / \mathrm{A}$ ratio being equal to 5.84 pr.diopter/ diopter and higher; if they also had their axial refraction being equal to +0.75 and even more, risks additionally increased by 3.21 times [35]. Increased AC/A ratio as a risk factor that caused myopia was also mentioned during the following 1-4 years in other research works.

Intraocular pressure. We haven't found any convincing facts that intraocular pressure exerts any influence on myopia occurrence.

There are some other factors mentioned in scientific literature that can cause myopia; they are thickness and refracting power of the lens [25], size and type of astigmatism $[25,26]$, spherical aberration sign and some others.

If myopia is prevented or at least its occurrence is postponed, it can reduce risks of high myopia occurrence $[1,8]$. As is known, the later myopia develops the smaller its ultimate value is $[26,36]$, and any impacts exerted on myopic process with 33\% efficiency reduce frequency of high myopia by $73 \%$; $50 \%$ efficiency will result in a $90 \%$ decrease in frequency of high myopia [36].

Obviously, myopia among children should be dealt with; it is necessary to start from detecting and analyzing risk factors that cause its development among pre-school and junior school children. Certain risk factors that cause myopia such as heredity and anterior-posterior axis length can't be changed or eliminated. Others, such as too little time spent outdoors or considerably long and intense visual loads when working at a close distance can be removed. Prolonging time spent by children outdoors up to 10-14 hours per week, doing sports, additional educational loads being limited to 2 hours a day or less are efficient measures that can prevent myopia $[16,17,19$, and 20]. They are especially relevant for children whose parents have myopia in their case histories. Parents should control visual activities of their children, how their children use gadgets, how much time they spend watching TV, what postures they take when working at a close distance, how long their sleep is or whether they get enough rest; all these measures allow achieving more than a 2-times reduction in risks of myopia occurrence [13].

Central and peripheral refraction, accommodation, convergence and their interrelations as well as some other factors can be influenced via perifocal optical correction that corrects relative peripheral long sight [37]; via correction that compensates for insufficient accommodation and induces a myopic defocus in an eye [38]; training accommodation including special training glasses that can be used at home [39]; applying local drug therapy with $\alpha$-adrenoceptor antagonists, M-cholinergic antagonists and their combinations [40].

Conclusion. Myopia becomes more and more frequent with each subsequent generation. Overall trend is that a number of people with myopia is growing all over the world including those suffering from high myopia.

The most significant factors that cause myopia are heredity (especially if both parents are short-sighted or one of them suffers from high myopia), pseudomyopia, refraction that is stronger than 0.75 diopter hypermetropia, greater anterior-posterior axis length, and high AC/A ratio. Significant influence is also exerted by environmental factors, education, and urbanization. There are a lot of convincing evidences that there is a tight correlation between genetic factors and impacts exerted by the environment. Behav- 
ioral factors are also very important; they include time spent actively outdoors, length and intensity of visual loads when working at a close distance.

It is vital to early detect risk factors and influence them directly or indirectly as it allows preventing myopia occurrence or postpone it for an older age. It, in its turn, will lead to high myopia becoming less frequent, reducing cases in which myopia gets complicated or turns into a grave form.

Funding. The research was not granted any sponsor support.

Conflict of interests. The authors state there is no any conflict of interests.

\section{References}

1. Wojciechowski R. Nature and nurture: the complex genetics of myopia and refractive error. Clin. Genet, 2011, vol. 79, no. 4, pp. 301-320. DOI: 10.1111/j.1399-0004.2010.01592.x

2. Proskurina O.V., Markova E.Y., Brzheskij V.V., Efimova E.L., Efimova M.N., Chvatova N.N., Slychalova N.N., Egorova A.V. Prevalence of Myopia in Schoolchildren in Some Regions of Russia. The Ophthalmology in Russia, 2018, vol. 15, no. 3, pp. 348-353 (in Russian). DOI: 10.18008/1816-5095-2018-3-348-353

3. Foster P.J., Jiang Y. Epidemiology of myopia. Eye (Lond), 2014, vol. 28, no. 2, pp. 202-208. DOI: $10.1038 /$ eye.2013.280

4. Morgan I.G., French A.N., Ashby R.S., Guo X., Ding X., He M., Rose K.A. The epidemics of myopia: Aetiology and prevention. Prog. Retin. Eye Res, 2018, vol. 62, no. 1, pp. 134-149. DOI: 10.1016/j.preteyeres.2017.09.004

5. Wolfram C., Höhn R., Kottler U., Wild P., Blettner M., Bühren J., Pfeiffer N., Mirshahi A. Prevalence of refractive errors in the European adult population: the Gutenberg Health Study (GHS). Br. J.Ophthalmol, 2014, vol. 98, no. 7, pp. 857-861. DOI: 10.1136/bjophthalmol-2013-304228

6. Holden B.A., Fricke T.R., Wilson D.A., Jong M., Naidoo K.S., Sankaridurg P., Wong T.Y., Naduvilath T.J., Resnikoff S. Global prevalence of myopia and high myopia and temporal trends from 2000 through 2050. Ophthalmology, 2016, vol. 123, no. 5, pp. 1036-1042. DOI: 10.1016/j.ophtha.2016.01.006

7. Tano Y. Pathologic myopia: where are we now? Am. J. Ophthalmol, 2002, vol. 134, no. 5, pp. 645-660. DOI: 10.1016/S0002-9394(02)01883-4

8. Jones-Jordan L.A., Sinnott L.T., Manny R.E., Cotter S.A., Kleinstein R.N., Mutti D.O, Twelker J.D., Zadnik K. [et al.]. Early childhood refractive error and parental history of myopia as predictors of myopia. Invest. Ophthalmol. Vis. Sci, 2010, vol. 51, no. 1, pp. 115-121. DOI: 10.1167/iovs.08-3210

9. Wu M.M., EdwardsM.H. The effect of having myopic parents: an analysis of myopia in three generations. Optom. Vis Sci, 1999, vol. 76, no. 6, pp. 387-392.

10. Zadnik K., Satariano W.A., Mutti D.O., Sholtz R.I., Adams A.J. The effect of parental history of myopia on children's eye size. JAMA, 1994, vol. 271, no. 17, pp. 1323-1327.

11. Mutti D.O., Hayes J.R., Mitchell G.L., Jones L.A., Moeschberger M.L., Cotter S.A., Kleinstein R.N., Manny R.E., Twelker J.D., Zadnik K. [et al.]. Refractive error, axial length, and relative peripheral refractive error before and after the onset of myopia. Invest. Ophthalmol. Vis. Sci, 2007, vol. 48, no. 6, pp. 2510-2519. DOI: 10.1167/iovs.06-0562

12. Garner L.F., Owens H., Kinnear R.F., Frith M.J. Prevalence of myopia in Sherpa and Tibetan children in Nepal. Optom. Vis. Sci, 1999, vol. 76, no. 5, pp. 282-285.

13. Zhou S., Yang L., Lu B., Wang H., Xu_T., Du D., Wu S., Li X., Lu M. Association between parents' attitudes and behaviors toward children's visual care and myopia risk in school-aged children (meta-analis). Medicine, 2017, vol. 96, no. 52, pp. e9270. DOI: 10.1097/MD.0000000000009270

14. Avetisov E.S. Blizorukost': monografiya [Myopia: a monograph]. Moscow, Meditsina Publ., 1999,186 p. (in Russian).

15. Gray C., Gibbons R., Larouche R., Sandseter E.B.,Bienenstock A., Brussoni M., Chabot G., Herrington S. [et al.]. What is the relationship between outdoor time and physical activity, sedentary behaviour, and physical fitness in children? A systematic review. Int. J. Environ Res. Public Health, 2015, vol. 12, no. 6, pp. 6455-6474. DOI: 10.3390/ijerph120606455 
16. Rose K.A., Morgan I.G., Ip_J., Kifley_A., Huynh S., Smith W., Mitchell P. Outdoor activity reduces the prevalence of myopia in children. Ophthalmogy, 2008, vol. 115, no. 8, pp. 1279-1285. DOI: $10.1016 /$ j.ophtha.2007.12.019

17. Wu P.C., Tsai C.L., Wu H.L., Yang Y.H., Kuo H.K. Outdoor activity during class recess reduces myopia onset and progression in school children. Ophthalmology, 2013, vol. 120, no. 5, pp. 1080-1085. DOI: 10.1016/j.ophtha.2012.11.009

18. Deng L., Pang Y. Effect of outdoor activities in myopia control: meta-analysis of clinical studies. Optom. Vis Sci,_2019, vol. 96, no. 4, pp. 276-282. DOI: 10.1097/OPX.0000000000001357

19. Saxena R., Vashist_P., Tandon_R., Pandey R.M., Bhardawaj A., Menon V., Mani K. Prevalence of myopia and its risk factors in urban school children in Delhi: the North India Myopia Study (NIM Study). PLoS One, 2015, vol.10, no. 2, pp. e0117349. DOI: 10.1371/journal.pone.0117349

20. Rose K.A., Morgan I.G., Smith W., Burlutsky_G., Mitchell P., Saw S.M. Myopia lifestyle and schooling in students of Chinese ethnicity in Singapore and Sydney. Arch. Ophthalmol, 2008, vol. 126, no. 4, pp. 527-530. DOI: 10.1001/archopht.126.4.527

21. Huang H.M., Chang D.S.T., Wu P.C. The Association between near work activities and myopia in children - a systematic review and meta-analysis. PLOS ONE, 2015, vol. 10, no. 10, pp. e0140419. DOI: 10.1371 journal.pone.0140419

22. Saw S.M., Chua W.H., Hong C.Y., Wu H.M., Chan W.Y., Chia K.S., Stone R.A., Tan D. Nearwork in early-onset myopia. Invest. Ophthalmol. Vis. Sci, 2002, vol. 43, no. 2, pp.332-339.

23. Holton V., Hinterlong_J.E., Tsai C.Y., Tsai J.C., Wu J.S., Liou_Y.M. A nationwide study of myopia in taiwanese school children: family, activity, and school-related factors. J. Sch. Nurs, 2019, vol. 13, p. 1059840519850619 . DOI: $10.1177 / 1059840519850619$

24. Mutti D.O., Mitchell G.L., Moeschberger M.L., Jones L.A., Zadnik K. Parental myopia, near work, school achievement, and children's refractive error. Invest. Ophthalmol. Vis. Sci., 2002, vol. 43 , no. 12 , pp. $3633-3640$.

25. Zadnik K., Sinnott L.T., Cotter S.A., Jones-Jordan L.A., Kleinstein R.N., Manny R.E., Twelker J.D., Mutti D.O. [et al.]. Prediction of juvenile-onset myopia. JAMA Ophthalmol, 2015, vol. 133, no. 6, pp. 683-689. DOI: 10.1001/jamaophthalmol.2015.0471

26. Onufriychuk O.N., Rozenblum Yu.Z. Regularities of the refractive genesis of school myopathy and criteria for its prediction. Vestnik oftal'mologii, 2007, no. 6, pp. 22-24.

27. He X., Zou H., Lu L., Zhao R., Zhao H., Li Q., Zhu J. Axial length/corneal radius ratio: association with refractive state and role on myopia detection combined with visual acuity in Chinese schoolchildren. PLoS One, 2015, vol. 10, no. 2, pp. e0111766. DOI: 10.1371/journal.pone.0111766

28. Schmid G.F. Association between retinal steepness and central myopic shift in children. Opt. Vis. Sci, 2011, vol. 88, no. 6, pp. 684-690. DOI: 10.1097/OPX.0b013e3182152646

29. Lundström L., Mira-Agudelo A., Artal P. Peripheral optical errors and their change with accommodation differ between emmetropic and myopic eyes. Journal of vision, 2009, vol. 9, no. 6, pp. 1-11. DOI: 10.1167/9.6.17

30. Mutti D.O., Mitchell G.L., Hayes J.R., Jones L.A., Moeschberger M.L., Cotter S.A., Kleinstein R.N., Manny R.E. [et al.]. Accommodative lag before and after the onset of myopia. Invest. Ophthalmol Vis Sci, 2006, vol. 47, pp. 837-846. DOI: 10.1167/iovs.05-0888

31. Charman W.N. Near vision, lags of accommodation and myopia. Ophthalmic Physiol. Opt., 1999, vol. 19, no. 2, pp. 126-133.

32. Goss D.A., Jackson T.W.Clinical findings before the onset of myopia in youth: 2. Zone of clear single binocular vision. Optom. Vis. Sci, 1996, vol. 73, no. 4, pp. 263-268.

33. Dashevskii A.I. Razvitie psevdomiopii i miopii i ikh profilaktika [Myopia and pseudomyopia: development and prevention]. Vestnik oftal'mologii, 1988, no. 3, pp. 132-136 (in Russian).

34. Sreenivasan V., Irving E.L., Bobier W.R. Effect of heterophoria type and myopia on accommodative and vergence responses during sustained near activity in children. Vision Research, 2012, vol. 57, pp. 9-17. DOI: 10.1016/j.visres.2012.01.011

35. Mutti D.O., Mitchell G.L., Jones-Jordan L.A., Cotter S.A., Kleinstein R.N., Manny R.E., Twelker J.D., Zadnik K. [et al.]. The response AC/A ratio before and after the onset of myopia. Invest. Ophthalmol. Vis. Sci, 2017, vol. 58, no. 3, pp. 1594-1602. DOI: 10.1167/iovs.16-19093 
36. Brennan N.A. Predicted reduction in high myopia for various degrees of myopia control. Cont. Lens Anterior Eye, 2012, vol. 35, no. 1, pp. 14-15. DOI: 10.1016/j.clae.2012.08.046

37. Ibatulin R.A., Proskurina O.V., Tarutta E.P. Multi-Factoral Mechanisms of Therapeutic Effect of Perifocal Spectacles (Perifocal-M) on Progressive Myopia in Children. Oftal'mologiya, 2018, vol. 15, no. 44, pp. 433-438 (in Russian). DOI: 10.18008/1816-5095-2018-4-433-438

38. Filinova O.B. Filinova O.B. Dynamics of refraction and muscular balance in children on the background of permanent mild-myopic defocusing in binocular and monocular alternating format. Rossiiskaya pediatricheskaya oftal'mologiya, 2009, no. 1, pp. 31-33 (in Russian).

39. Proskurina O.V., Tarasova N.A., Tarutta E.P., Proskurina O.V., Tarasova N.A., Tarutta E.P. Accommodation disorders often precede the development and progression of myopia in children. Modern optometry, 2018, vol. 118, no. 8, pp. 25-29 (in Russian).

40. Vorontsova T.N. Results of medication therapy of habitually excessive tension of accommodation in children and higher-school students. Rossiiskii Oftal'mologicheskii Zhurnal, 2016, vol. 9, no. 2, pp. 18-21 (in Russian). DOI: 10.21516/2072-0076-2016-9-2-18-21

Tarutta E.P., Proskurina O.V., Tarasova N.A., Markosyan G.A. Analysis of risk factors that cause myopia in pre-school children and primary school students. Health Risk Analysis, 2019, no. 3, pp. 26-33. DOI: 10.21668/health.risk/2019.3.03.eng

Received: 12.07 .2019

Accepted: 08.08.2019

Published: 30.09 .2019 
UDC 504.5

DOI: 10.21668/health.risk/2019.3.04.eng

\title{
NANO- AND MICRO-PARTICLES CONCENTRATIONS IN WORKING AREA AIR AT GALVANIC PRODUCTION: PILOT RESEARCH
}

\author{
K.S. Golokhvast ${ }^{1}$, K.Yu. Kirichenko ${ }^{1}$, P.F. Kiku ${ }^{1}$, N.V. Efimova ${ }^{2}$, M.F. Savchenkov ${ }^{3}$, \\ I.A. Vakhnyuk ${ }^{1}$, D.Yu. Kosyanov', S.A. Medvedev ${ }^{4}$, V.P. Soparev', V.A. Drozd ${ }^{1}$ \\ ${ }^{1}$ Far Eastern Federal University, 8 Sukhanova Str., Vladivostok, 690091, Russian Federation \\ ${ }^{2}$ East-Siberian Institute of Medical and Environmental Research, 3A, 12A Mikroraion Str., Angarsk, 665827, \\ Russian Federation \\ ${ }^{3}$ Irkutsk State Medical University, 2 Krasnogo Vosstania Str., Irkutsk, 664003, Russian Federation \\ 4“Izumrud” joint-stock company, 65 Russkaya Str., Vladivostok, 690105, Russian Federation \\ 5“Dalpribor" PLC, 46/50 Borodinskaya Str., Vladivostok, 690105, Russian Federation
}

Electrochemical processes that involve making protective coats at contemporary galvanic productions are widely spread in various industries. As chemically active solutions and heavy metals are usually applied in galvanic production, it can be ranked among hazardous ones. Our research goal was to examine morphometric parameters of nano- and micro-particles that were detected in working area air at enterprises where galvanic baths and electrochemical processes were applied.

To perform a complex examination of particle-size distribution and concentration of a galvanic aerosol (GA) in working area air, we applied a combined procedure that included:

1) measuring qualitative structure of particulate matter $\left(\mathrm{mg} / \mathrm{m}^{3}\right)$ according to ISO 21501-4 in order to determine concentrations of $P M_{0.3}, P M_{0.5}, P M_{1}, P M_{3}, P M_{5}$, and $P M_{10}$ with a portable laser meter;

2) measuring mass concentrations of $P M_{10}$ according to the European Standard for determining particulate matter EN 12341:2014;

3) measuring particle-size structure of particulate matter via deposition with laser granulometry.

Quantities of particles that belonged to $P M_{0,3}$ fraction were more than 10,000 times higher in working area air inside a galvanic workshop that quantities of those belonging to $P M_{10}$ fraction. Maximum quantities of particles were detected near a nickel-plating bath. Mass concentration of $P M_{10}$ fraction amounted to $0.04 \pm 0.0001 \mathrm{mg} / \mathrm{m}^{3}$. Contents of particles with their size exceeding $700 \mu \mathrm{m}$ accounted for 30-90\% of the overall quantities of particles at most examined points; particles with their size being less than $10 \mu \mathrm{m}$ were detected only in an area where aluminum was being hardened.

Quality of working area air at galvanic production doesn't fully provide safe working conditions due to ultra-thin fractions prevalence in industrial aerosols; it can result in so called "sub-threshold effects" causing bronchopulmonary diseases.

Key words: working area, galvanic production, working conditions, air quality, industrial aerosols, nano-and microparticles.

(c) Golokhvast K.S., Kirichenko K.Yu., Kiku P.F., Efimova N.V., Savchenkov M.F., Vakhnyuk I.A., Kosyanov D.Yu., Medvedev S.A., Soparev V.P., Drozd V.A., 2019

Kirill S. Golokhvast - Doctor of Biological Sciences, Corresponding Member of the Russian Academy of Education, Professor of the Russian Academy of Sciences Professor at the Department of Life Safety in the Technosphere (e-mail: droopy@mail.ru; tel.: +7 (924) 126-13-13; ORCID: https://orcid.org/0000-0002-4873-2281).

Konstantin Yu. Kirichenko - Candidate of Biological Sciences, Researcher at the Research and Educational Center for Nanotechnologies (e-mail:Kirichenko2012@gmail.com; tel.: +7 (950) 285-76-57; ORCID: https://orcid.org/0000-0002-2715-3758).

Pavel F. Kiku - Doctor of Medical Sciences, Candidate of Technical Sciences, Professor, Head of the Department for Public Health and Preventive Medicine (e-mail: lme@list.ru; tel.: +7 (902) 555-48-91; ORCID: https://orcid.org/my-orcid/00000003-3536-8617).

Nataliya V. Efimova - Doctor of Medical Sciences, Professor, Leading Researcher at the Laboratory of Ecological and Hygienic Research (e-mail: medecolab@inbox.ru; tel.: +7 (914) 892-19-47; ORCID: http://orcid.org/0000-0001-7218-2147).

Mikhail F. Savchenkov - Doctor of Medical Sciences, Academician of the Russian Academy of Sciences, Professor, Professor of the Common Hygiene Department (e-mail: smf36@mail.ru; tel.: +7 (395) 224-38-43; ORCID: http://orcid.org/0000-0002-1246-8327).

Igor A. Vakhnuk - Postgraduate Student (e-mail: vahnuk86@mail.ru; tel.: +7 (904) 628-10-88).

Denis Y. Kosyanov - Candidate of Technical Sciences, Senior Researcher at the Laboratory of Electronic Structure and Quantum-Chemical Modeling, Department of General and Experimental Physics (e-mail: kosianov.diu@dvfu.ru; tel.: +7 (984) 156-64-80).

Stanislav A. Medvedev - Deputy Director responsible security at «Izumrud» Stock Company (e-mail: MedvedevStanislav-79@mail.ru; tel.: +7 (908) 448-85-35).

Viktor P. Soparev - Deputy Chief Technologist at «Dalpribor» Public Stock Company (e-mail: soparev@mail.ru; tel.: +7 (914) 7959870).

Vladimir A. Drozd - Radiation Safety Engineer at the Research and Educational Center for Nanotechnologies (e-mail: v_drozd@mail.ru; tel.: +7 (924) 733-12-7). 
Electrochemical processes at contemporary galvanic production are applied to make protective coats and can be met in various branches including defense and aerospace industries. Galvanic production is considered to be hazardous due to chemically active solutions and heavy metals being widely used in it. As per data provided by Rosstat a specific weight of workers employed at adverse and (or) hazardous productions grows annually $[1,2]$. As is well known, hazardous substances penetrate a worker's body not only through the respiratory tracts but also through the skin, ears, eyes, and other unprotected parts of a body [3]. Permanent exposure to negative factors existing at galvanic production causes occupational diseases, mostly in the respiratory organs and upper respiratory tracts, circulatory system, and the musculoskeletal system when working experience at such a production is from 10 to 15 years. Suspensions rich with nano- and micro-particles of heavy metals essentially occur in the air in a workshop where electrochemical processes take place; it is a significant factor for creating programs aimed at protecting workers' health. It is necessary to implement efficient prevention activities and apply protection means for workers employed at hazardous productions and workers with allied occupations if we want to reduce a number of disease cases and risks of lethal outcomes. The task can be solved only after assessing morphometric parameters of nano- and micro-particles as well as properties of particles in an industrial aerosol that occurs in a galvanic workshop.

Nano- and micro-sized suspensions in the atmosphere are detected at points that are quite remote from industrial buildings [4-6], they exert considerable influence on climate in industrial centers [7], and technogenic particles account for $45 \%$ out of overall aerosol particles [8]; nevertheless, contamination of working area air at galvanic production and adjoining territories with nano- and micro-sized suspensions hasn't been given relevant attention. If we fail to assess significance and hazards caused by nanotechnological contamination, it can cre- ate health risks for population and makes certain areas less socially and economically attractive [9]. Working conditions have a key role in protecting population health and health of welders in particular. Microclimate at a working place matters a lot as a person consumes $15 \mathrm{~kg}$ of air per day. Unsatisfactory microclimatic parameters cause occupational diseases. Particles with their size being up to $10 \mu \mathrm{m}$ are the most hazardous for human health due to their ability to cause respiratory diseases [10-12].

Previously we detected nano- and microparticles within sanitary protection zones around industrial enterprises that had galvanic workshops in their structure [5]. In particular, we'd like to mention suspended $\mathrm{Fe}$ and $\mathrm{Cr}$ particles with their diameter being equal to $10-120 \mathrm{~nm}$ and their share accounting for up to $76 \%$; however, we couldn't detect a source and a mechanism of their occurrence.

Issues related to nano-particles penetrating working area air remain outstanding. In particular, there are no criteria for assessing exposure to nanoparticles; as the chemical structure of particulate matter is usually a multi-component one, there are not enough data on potential toxicological effects produced by exposure to them and it creates significant difficulties for experts who try to substantiate hygienic standards in the sphere.

Our research goal was to perform complex analysis of nano- and micro-particles contents in working area air as a factor causing health risks for workers employed at enterprises where electroplating baths and electrochemical processes were applied.

Data and methods. We performed our research in a galvanic workshop where basic technological processes were aluminum clarification and pickling; sulfuric anodic treatment; chemical and electric aluminum degreasing; removal of sludges after pickling; non-ferrous metals pickling; chrome and nickel plating. To perform a complex examination of particle-size distribution and concentration of a galvanic aerosol (GA) in working area air, we applied a combined procedure that included: 
1) measuring quantitative structure of particulate matter $(\mathrm{mg} / \mathrm{m} 3)$ according to ISO 21501-4 in order to determine concentrations of PM0.3, PM0.5, PM1, PM3, PM5, and PM10 with a portable laser meter;

2) measuring mass concentrations of PM10 according to the European Standard for determining particulate matter EN 12341:2014;

3) measuring particle-size structure of particulate matter via deposition with laser granulometry.

1. Measuring quantitative structure of particulate matter. To quantitatively analyze and determine particles concentrations in working area air we applied a hand laser Aero Trak Handheld Particle Counter 9306 (the USA). The model 9306 conforms to all the requirements fixed in ISO 21501-4. Samples at each point were taken during 1 minute. Overall air volume that passed through the device amounted to $2.83 \mathrm{1} / \mathrm{min}$ and it was within its recommended functioning modes. Samples were taken at 1.5 meters height as it corresponded to a height at which a person usually breathes; all sampling points were located directly above an open electrolyte of an electroplating bath. Overall, we examined 11 electroplating baths in our experiment which were included into technological processes at three production lines: a line where aluminum was being prepared; a line where non-ferrous metals were being prepared; and a line where protection covers were being made. The list of sampling points and electrolytes applied in production processes is given in Table 1.

We performed 5 measurements for each type of an electroplating bath $(\mathrm{N}=60)$ in our experiment.

2. Measuring mass concentrations of particulate matter. To determine concentrations of aerosol particles $\left(\mathrm{mg} / \mathrm{m}^{3}\right)$ in working area air in a galvanic workshop, we took a series of samples near stationary electroplating baths. We chose a gravimetric procedure to measure concentrations of GA particles and used an aspiratory LVS 3.1 type sampler (Ingeniero Nobert Derenda, Germany). This sampler has a nozzle for sampling $\mathrm{PM}_{10}$ fraction and is also equipped with $47 \mathrm{~mm}$ nylonbased filters Nylon 66 Membranes without connections and their working surface diameter being $47 \mathrm{~mm}$ (SUPERLCOUSA). Flowing capacity of the filters amounted to $0.45 \mu \mathrm{m}$. Thereby, an examined range of particulate matter varied from $0.45 \mu \mathrm{m}$ to $10 \mu \mathrm{m}$. We chose $10 \mu \mathrm{m}\left(\mathrm{PM}_{10}\right)$ as an upper limit of the particles fraction as it is well in line with modern trends in control over particulate matter in the atmosphere [13-16].

Table 1

Technological processes at a galvanic workshop

\begin{tabular}{|c|l|c|c|}
\hline No. & \multicolumn{1}{|c|}{ A technological processes } & Electrolyte structure & $\begin{array}{c}\text { Production line } \\
\text { for preparing }\end{array}$ \\
\hline 1 & Background territory (offices) & - & - \\
\hline 2 & Aluminum clarification & $\mathrm{HNO}_{3}$ & Aluminum \\
\hline 3 & Aluminum pickling & $\mathrm{NaOH}$ & Aluminum \\
\hline 4 & Sulfuric anodic treatment & $\mathrm{H}_{2} \mathrm{SO}_{4}$ & Aluminum \\
\hline 5 & Aluminum degreasing & $\mathrm{Na}_{2} \mathrm{CO}_{3} ; \mathrm{Na}_{3} \mathrm{PO}_{4}$ & Aluminum \\
\hline 6 & Chemical degreasing & $\mathrm{Ja}_{0} \mathrm{Mu}_{2} 203$ & Non-ferrous metals \\
\hline 7 & Electrical degreasing & $\mathrm{Na}_{2} \mathrm{CO}_{3} ; \mathrm{Na}_{3} \mathrm{PO}_{4}$ & Non-ferrous metals \\
\hline 8 & Removal of sludges after pickling & $\mathrm{Cr}_{2} \mathrm{O}_{3} ; \mathrm{H}_{2} \mathrm{SO}_{4} ; \mathrm{NaCl}$ & Non-ferrous metals \\
\hline 9 & Non-ferrous metals pickling & $\mathrm{HNO}_{3} ; \mathrm{H}_{2} \mathrm{SO}_{4} ; \mathrm{HCl}$ & Non-ferrous metals \\
\hline 10 & Chrome plating & $\mathrm{H}_{2} \mathrm{CrO}_{4} ; \mathrm{H}_{2} \mathrm{SO}_{4}$ & Non-ferrous metals \\
\hline 11 & Nickel plating & $\mathrm{NiSO}_{4} ; \mathrm{MgSO}_{4} ; \mathrm{Na}_{2} \mathrm{SO}_{4} ; \mathrm{NaCl} ; \mathrm{H}_{3} \mathrm{BO}_{3}$ & Non-ferrous metals \\
\hline 12 & Chemical nickel plating & $\mathrm{NiSO}_{4} ; \mathrm{MgSO}_{4} ; \mathrm{Na}_{2} \mathrm{SO}_{4} ; \mathrm{NaCl} ; \mathrm{H}_{3} \mathrm{BO}_{3}$ & Non-ferrous metals \\
\hline
\end{tabular}


Table 2

Particle size distribution for an industrial aerosol in a galvanic workshop, units $/ 100 \mathrm{~cm}^{3}$

\begin{tabular}{|c|l|c|c|c|c|c|c|}
\hline № & \multicolumn{1}{|c|}{ Sampling point } & $\mathrm{PM}_{0,3}$ & $\mathrm{PM}_{0,5}$ & $\mathrm{PM}_{1}$ & $\mathrm{PM}_{3}$ & $\mathrm{PM}_{5}$ & $\mathrm{PM}_{10}$ \\
\hline 0 & Background territories (offices) & 159,643 & 29,317 & 2,318 & 196 & 74 & 10 \\
\hline 1 & Aluminum clarification & $19,247,204$ & $3,126,713$ & 269,112 & 42,071 & 18,171 & 2,282 \\
\hline 2 & Aluminum pickling & $18,774,926$ & $2,858,021$ & 234,399 & 34,086 & 13,895 & 1,711 \\
\hline 3 & Sulfuric anodic treatment & $18,758,289$ & $3,134,410$ & 286,763 & 48,169 & 20,977 & 2,938 \\
\hline 4 & Aluminum degreasing & $28,703,393$ & $6,005,978$ & 338,080 & 35,892 & 14,768 & 1,766 \\
\hline 5 & Chemical degreasing & $16,610,093$ & $4,995,215$ & $1,119,675$ & 459,242 & 273,288 & 44,287 \\
\hline 6 & Electrical degreasing & $23,821,193$ & $4,836,159$ & 290,667 & 36,512 & 15,388 & 2,186 \\
\hline 7 & Removal of sludges after pickling & $19,961,226$ & $3,427,211$ & 250,587 & 33,378 & 13,710 & 1,666 \\
\hline 8 & Non-ferrous metals pickling & $20,526,593$ & $3,053,826$ & 237,555 & 30,997 & 12,420 & 1,600 \\
\hline 9 & Chrome plating & $10,932,963$ & $1,671,387$ & 181,983 & 24,534 & 9,946 & 1,150 \\
\hline 10 & Nickel plating & $20,245,996$ & $3,689,208$ & 337,626 & 33,953 & 12,332 & 1,180 \\
\hline 11 & Chemical nickel plating & $31,279,133$ & $10,266,759$ & 715,403 & 22,772 & 6,628 & 406 \\
\hline
\end{tabular}

Prior to sampling the filters had been dried in TC-1/20 thermostat (Russia) for 24 hours at $40{ }^{\circ} \mathrm{C}$; after that each filter was weighted 5 times with an electronic balance Sartorius (Germany) and a mean value for a weight was determined. Readings were taken at 5 points in a galvanic workshop; those points were located at a distance from 1 to 5 meters away from stationary nickel plating baths as such baths were sources of the most toxic particles. The nozzle was fixed at 1.5 meters height as it corresponded to a height at which a person usually breathes. We obtained 10 sets of data for each type of an electroplating bath $(\mathrm{N}=50)$ in our experiment.

3. Measuring particle-size structure of particulate matter via deposition. To perform particle-size analysis for particles contained in working area air, we took samples via the following procedure: we placed sterile plastic containers on the workshop floor where workers performed their tasks in a workshop; a volume of each container amounted to 2.7 liters and they were all filled with distilled water (this water treatment procedure completely removes any particulate matter from water) obtained with DE-4-02-EMO water distillation device ("Electromedoborudovanye" LLC, Saint Petersburg, Russia). Particles settled into open containers. The procedure was chosen due to a possibility to collect the whole range of nano- and micro-particles as it is not the case with any other alternative method (any applied filter has a minimal size equal to 430 $\mathrm{nm}$ and it means that smaller particles pass through it freely). Prior to the experiment all the containers had been thoroughly washed, firstly with running water, and then twice with distilled water; after it the containers were filled with $600-800 \mathrm{ml}$ of distilled water which amounted to $1 / 3$ of their overall volume. We wrote down a denomination of an electroplating bath for each sample as well as a date and time at which it was taken.

Our experiment lasted for 8 hours as it was equal to working shift duration in the chosen workshop. The containers were placed close to operating stationary electroplating baths and were open at 8 a.m. just as a working shift started. As the shift ended at 17 p.m., the containers were tightly closed, marked and transported to a laboratory for further research.

Results were statistically processed with "Statistica 10.0" software package; we assessed statistical significance of parameters and discrepancies between examined samplings as per Student's t-test taking into account a type of values distribution.

Results and discussion. Having examined particle-size distribution, we detected that the smallest particles prevailed absolutely (Table 2).

A quantity of $\mathrm{PM}_{0,3}$ (particles smaller than $0.3 \mu \mathrm{m}$ ) was more than 10,000 times 